The Problem of Known Illusion and the Resemblance of Experience to Reality

\author{
Eric Schwitzgebel \\ Department of Philosophy \\ U.C. Riverside \\ Riverside, CA 92521-0201
}

June 15, 2013 


\section{The Problem of Known Illusion and the Resemblance of Experience to Reality}

\section{Introduction.}

If John Locke (1690/1975) is right, color might not be a feature of things as they are in themselves, but shape is a feature of those things. If I see a cube in normal conditions and rightly judge that it is a cube, then by gum there really is a mind-independent cubical thing out there, the shape of which in some important way resembles my experience of its shape. If Immanuel Kant (1781/1787/1929) is right, then John Locke is wrong about this. Things in themselves aren't cubical - or at least we have no good reason to think they are cubical. They're not laid out in space. There's nothing independent of the human mind that has cubical properties that resemble the properties of my visual experience of cubes.

I'd like to know if Locke is right or Kant is right. Do things as they are in themselves have shapes that resemble, in some important way, my experience of those shapes, or not? Are things, really, like this [here I gesture, through an act of attention, at my own visual experience]? Or is this just a sheen, a convenient interface experience, a human construction atop a radically different reality?

This might seem a hard question to answer.

I don't have an answer. But I do have a thought about a way in. My thought is this. Suppose it's the case that there are multiple different ways of veridically visually experiencing the same object, so that we can't say "this way is right and this way is wrong" or "this way is preferred over this other way". And then suppose further that sometimes it is also the case that there is no good reason to think that one of those two experiences more closely resembles how the experienced object is in itself. From these suppositions, it would seem to follow that there's a kind of looseness between the features of experience and the features of things in themselves. 
Things in themselves might be more like this or they might be more like that. They might more closely resemble experience A or they might more closely resemble experience B. Or they might really resemble neither experience very well. Thus, we get at least some bracketing parameters: We can no longer say we know that things in themselves are like this, at least in whatever respect this differs from that - a miniature Kantian victory over Locke.

To clarify what I have in mind here, I will focus on two examples.

\section{2. “Objects in Mirror Are Closer Than They Appear".}

According to the United States Code of Federal Regulations, Title 49, Chapter 5, $\S 571.111$, S5.4.2, pertaining to convex mirrors on passenger vehicles:

Each convex mirror shall have permanently and indelibly marked at the lower edge of the mirror's reflective surface, in letters not less than $4.8 \mathrm{~mm}$ nor more than $6.4 \mathrm{~mm}$ high the words “Objects in Mirror Are Closer Than They Appear" (GPO.gov, accessed July 13, 2011).

Here's a picture: 
Figure 1: Objects in mirror are closer than they appear

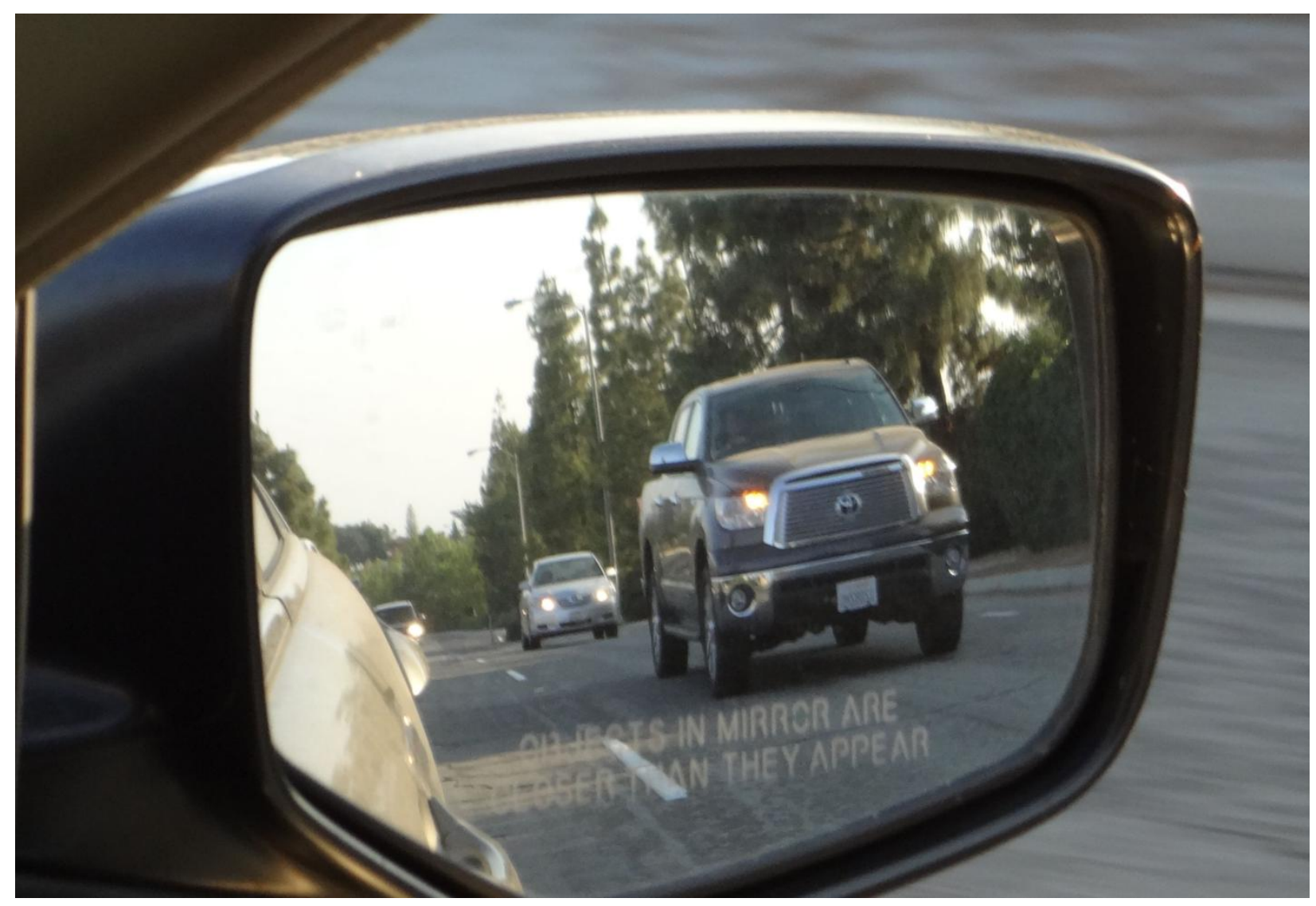

And here's a picture that contrasts how things look in a convex mirror with how they look in a flat mirror: 
Figure 2: The view in flat (on left) vs. convex (on right) driver's side mirrors

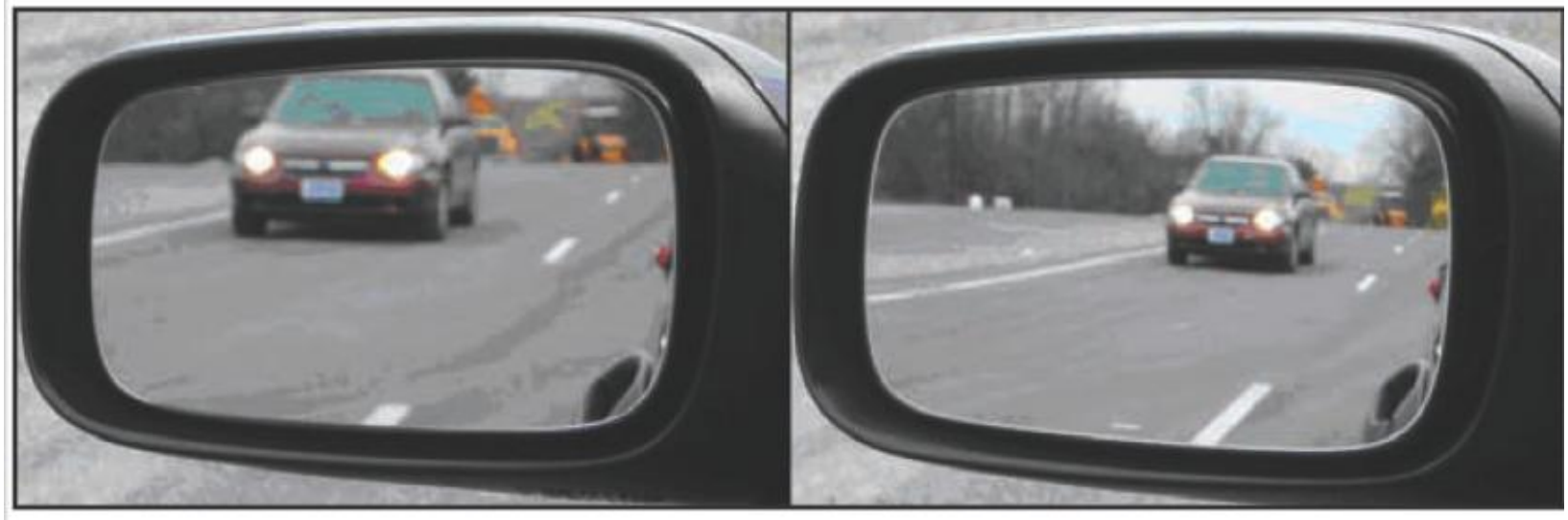

image detail from Wierwille et al. 2008

So consider: Are objects in the convex mirror closer than they appear?

Here are three possible answers:

(1.) Why yes, they are!

(2.) No, objects in the mirror aren't closer than they appear; but that's because rather than being closer than they appear they are larger than they appear. The convex mirror distorts size rather than distance.

(3.) No, objects in the mirror aren't closer than they appear; nor are they larger than they appear; if you're a skilled driver, the car behind you, as seen with the aid of the convex passenger-side mirror, is just where it looks to be and just the size it looks to be.

Answer (3) is the one I'm drawn to. One reason to favor the answer (3) is that there seem to be no good grounds to privilege saying that objects are closer than they appear in the convex mirror over saying that they are larger than they appear. It could be a 3-foot-tall car 30 feet away or a 6-foot-tall car 60 feet away. Nothing obvious about its appearance, as distorted by the mirror, decides between these two interpretations. But it also seems odd to just split the difference and say that it looks 4 1/2 feet tall and 45 feet away. If answers (1) and (2) each 
problematize each other, that might give us reason to favor answer (3). Another reason to favor the answer (3) is that skilled drivers are undeceived. Decades of auto safety research shows that practiced drivers do not misjudge the distance of cars in convex passenger-side mirrors. They don't misjudge when they are asked oral questions about the distance, nor do they misjudge when they make lane-shifting decisions in actual driving. Instead, they seem to skillfully and spontaneously use the mirror accurately to gauge the real distance of the cars behind them (e.g., de Vos 2000; Wierwille et al. 2008). This is not by itself a compelling reason to favor answer (3); presumably, anyone generally predisposed to think that the objects in the mirror are closer than they appear will allow that people familiar enough with the illusion might be entirely undeceived by it. But I hope you'll agree that there's something a bit happier about a position that avoids the proliferation of such undeceiving illusions, if an alternative theory is available.

A third kind of evidence for my preferred answer is introspective: Get in a car. Drive. Think about how the cars behind you look, both in the driver's-side and in the passenger's-side mirrors. Try adjusting the two mirrors so that they both point at the same car behind you when your head is centrally positioned in the cabin. Does the car look closer when your eyes are pointing toward the flat driver's-side mirror than when they're pointing toward the convex passenger's-side mirror? Based on my own messing around, I'm inclined to say no, the cars look the same distance in the two mirrors. I'm inclined toward what I will call the Multiple Veridicalities view. There's more than one way in which a car can look like it is 6 feet tall and 60 feet behind you. There's a flat-driver's-side mirror way and there's a convex passenger'sside-mirror way. And both ways are equally veridical. Flat mirrors aren't inherently more veridical; convex mirrors aren't inherently distortive. It's a matter of what we're used to. 
Anyhow, that's the view I'm inclined toward, partly on introspective grounds, partly on grounds of theoretical elegance. Now if it can be sustained, we can consider other cases of multiple veridicalities too: how things look through my new progressive-lens spectacles vs. how things look through my older single-correction prescription glasses; how the moon looks when it's near the horizon vs. how it looks at zenith; how the oar looks when partly immersed in water vs. how it looks in plain air. Is there more than one way in which the oar can "look straight"?

I do have a bit of trouble in good conscience acquiescing to the Multiple Veridicalities view in the oar case. What I'd like to be able to say is that to the truly skilled oar-in-water perceiver, the oar partly submerged in water no longer looks crooked. It looks straight. It looks just the way a straight oar should look when partly submerged in water. There are now just two different and equally good ways in which an oar can look straight - the plain air way and the half-submerged way, and neither experience more closely resembles the straightness of the oar as it is in itself. Maybe if we're inclined to think otherwise, that's only an accident of what is more common in our experience and what is less common. If there were, perhaps, a world in which every straight thing were always seen half-submerged in a refracting medium, we would say "that looks straight, straight, straight!" and when finally for the first time an oar was pulled into plain air we would say "oh, how crooked it looks; what an illusion!" As I said, that's what I'd like to say. It would be cool if it were true. But I'm not sure that I know that it's true.

If we treat the convex mirror case as I'd like to, then it seems we can construct a garden path to the oar case, via intermediate cases such as hypothetical windshields that contain a refractive portion to allow a broader field of view, skilled spearfishers who never aim wrong, corrective eyeglasses that habitually slip down the nose, head-mounted cameras, etc. We could consider jewelers with fish-eye lenses surgically installed, gods whose eyes are giant spheres in 
which we dwell, all kinds of hypothetical creatures to whom a square object might look very different than it looks to us. If would be delightful if we could treat all these cases in a unified way.

\section{Inverting Lenses.}

Let's consider a famous case from the history of psychology, the case of the inverting lenses.

Inverting lenses were first tried by George Stratton in the late 19th century $(1896,1897 \mathrm{a}-$ c). Stratton covered one eye and then presented to the other eye a field of view rotated 180 degrees, so that top was bottom and right was left. In his primary experiment, he wore this lens for the bulk of the day over the course of eight days, and he gives detailed introspective reports about his experience. Stratton adapted to his inverting lenses, as do others who wear the lenses for an extended period. But what does adapting consist in?

The simplest possibility to conceptualize, perhaps, is this: After adaptation, everything goes back to looking just the way it did before one donned the inverting lens. Let's say that preexperiment one looks out at the world - at, say, a lamp. Let's call the way things look, the way the lamp looks, before you put on the lens, "teavy". Now you put on the lens and everything seems to have rotated 180 degrees. Let's call that visual experience, that way the lamp looks to you now, "toovy". Over the course of adaptation, then, what happens on this view is that things go back - perhaps at first slowly, unstably, and disjointedly - to looking "teavy". After adaptation they look the same way they would have looked if you had never donned the inverting lens in the first place. This is the way adaptation to inverting lenses is often described, for 
example by James Taylor in his influential 1962 book and by Susan Hurley and Alva Noë in their 2003 article on the topic.

But there's another possibility - I think a more interesting one. That's the possibility that things remain toovy throughout. They never go back to teavy. But you get used to their looking toovy, so that you lose the normative sense that that's a wrong or misleading way for things to look. The lamp no longer looks "upside-down" in the normative sense of looking like the wrong side is on top; but it retains its "upside-down" look in the non-normative sense that the visual experience is the reverse of what it was before you put on the inverting lenses. To the adapted mind, there would now be two ways in which a lamp might look to be right-side up - the prelens teavy way and the post-lens toovy way. (Maybe toovy changes, too, as one accommodates - becoming toovy-prime, say, more richly and accurately layered with meaning and affordances; the important thing here is that it doesn't go back to teavy.) Just like with the convex mirror there would be multiple veridicalities - two ways of something's looking to have the same objective set of spatial properties and position and orientation relative to you.

Now it's an empirical question whether the Multiple Veridicalities view is correct about inverting lenses or whether things really do just go back to looking teavy after adaptation. And it's a tricky empirical question - one that requires I think a fairly subtle sense of what the possibilities are, a subtle sense of the different things one might mean by saying that something "looks like it is to the right or to the left" or "upside-down". As one might expect, the introspective reports of people who have tried inverting lenses are not entirely consistent or unequivocal. However, my assessment of the evidence is that the experimenters with the best nose for this sort of nuance - Stratton himself and then later Charles Harris $(1965,1980)$, favor 
the Multiple Veridicalities view. (See also Linden, Hallenbach, Heinecke, Singer, and Goebel 1999; Klein 2007). If so, there's more than one way for a lamp to look right-side up.

\section{Conclusion.}

I look out now upon the world; I imagine looking out upon it, just as veridically, through a fish-eye lens; I imagine looking out upon it, just as veridically, through increasingly weird assemblies that I would have said, the first time I gazed through them, made some distant things too large and some nearby things too small, that presented twists and gaps - maybe even that doubled some things while keeping others single - and to which I grow skillfully accustomed. I try to imagine my phenomenology not shifting back to what it was before, but remaining very different, while losing its sense of wrongness, so that I am no longer tempted to say that things in themselves are more like this than like that. I imagine extending this exercise to my other senses.

I'm not sure how far I can push this way of thinking, but the farther I can push it, the looser the relationship would seem to be between my experience of things and things as they are in themselves. My hunch is that numerosity and contiguity are the anti-Kantian's best hope for resemblance between things in themselves and one's experience of them - that a "toovy" (or "toovy-prime") visual experience from a visual array pieced-up and multiplied would lack some dimension of resemblance to things in themselves that ordinary visual experience has and that is still preserved in inversions and convex reflections.

Maybe Kant or some other philosopher has presented a sound a priori argument that our experiences can't really resemble things as they are in themselves in any useful sense of "resemble". I am exploring, instead, an empirical path that might lead at least partway toward 
the Kantian conclusion, grounded on introspective observation of variability among different seemingly equally veridical sensory experiences. ${ }^{1}$

${ }^{1}$ For helpful conversation during the course of writing, thanks to Scott Bakker, Robert Briscoe, Brit Brogaard, David Chalmers, Louie Favela, Jack Lyons, Farid Masrour, David Papineau, Kevin Reuter, Susanna Siegel, Houston Smit, Maja Spener, Nathan Westbrook, commenters on relevant posts at The Splintered Mind, and audiences at University of MissouriSt. Louis, and the Philosophy of Science Association. 


\section{References:}

de Vos, A. (2000). Non-planar driver's side rearview mirrors. United States Department of Transportation report. DOT HS 809149.

Harris, Charles S. (1965). Perceptual adaptation to inverted, reversed, and displaced vision. Psychological Review, 72, 419-444.

Harris, Charles S. (1980). Insight or out of sight? Two examples of perceptual plasticity in the human adult. In Visual coding and adaptability, ed. C.S. Harris. Hillsdale, NJ: Erlbaum. Hurley, Susan, and Alva Noë (2003). Neural plasticity and consciousness. Biology and Philosophy, 18, 131-168.

Kant, Immanuel (1781/1787/1929). Critique of pure reason. Trans. N.K. Smith. New York: St. Martin's.

Klein, Colin (2007). Kicking the Kohler habit. Philosophical Psychology, 20, 609-619.

Linden, David E.J., Ulrich Kallenbach, Armin Heinecke, Wolf Singer, and Rainer Goebel (1999). The myth of upright vision: A psychophysical and functional imaging study of adaptation to inverting spectacles. Perception, 28, 469-481.

Locke, John (1690/1975). Essay concerning human understanding. Ed. P.H. Nidditch. Oxford: Oxford.

Stratton, George M. (1896). Some preliminary experiences on vision without inversion of the retinal image. Psychological Review, 3, 611-617.

Stratton, George M. (1897a). Upright vision and the retinal image. Psychological Review, 3, $182-187$. 
Stratton, George M. (1897b). Vision without inversion of the retinal image. Psychological Review, 4, 341-360.

Stratton, George M. (1897c). Vision without inversion of the retinal image. Psychological Review, 4, 463-481.

Taylor, James G. (1962). The behavioral basis of perception. New Haven, CT: Yale.

Wierwille, Walter W., W.A. Schaudt, S. Gupta, J.M. Spaulding, D.S. Bowman, G.M. Fitch, D M. Wiegand, and R.J. Hanowski (2008). Study of driver performancelacceptance using aspheric mirrors in light vehicle applications. United States Department of Transportation report DOT HS 810959. 